\title{
A Comunicação Organizacional em uma perspectiva crítica
}

Critical perspectives on Organizational Communication

La Comunicación Organizacional en una perspectiva crítica

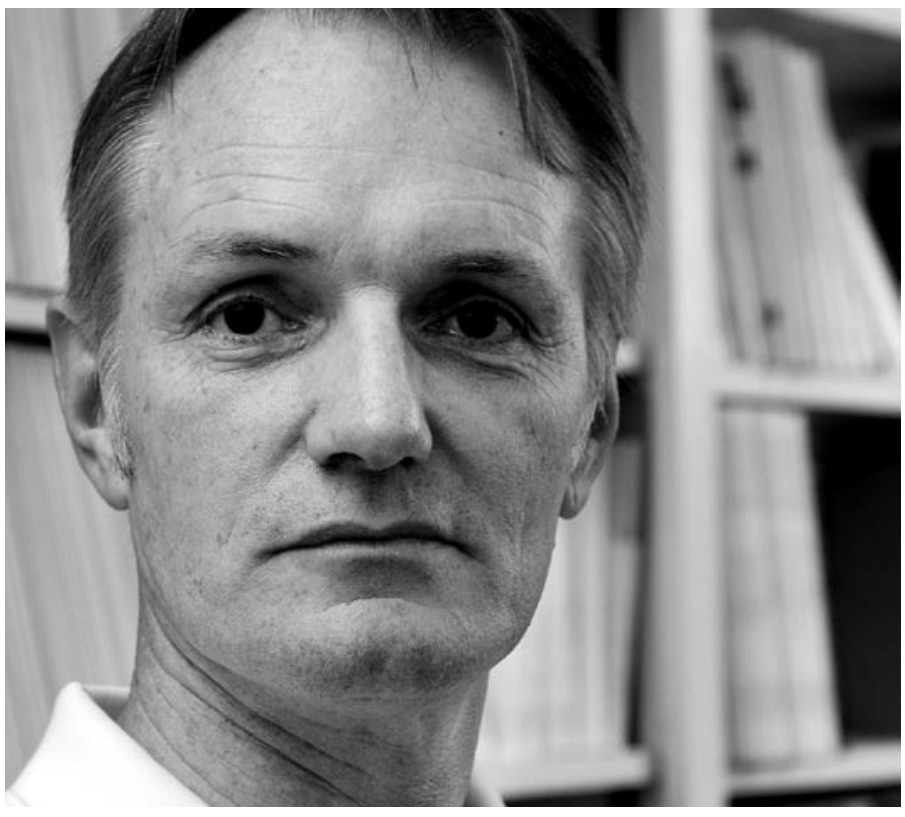

entrevista

Dennis K. Mumby 
D elgado, alto, meio tímido, sorriso franco e aberto, estilo descontraído, Dennis Mumby, inglês radicado nos Estados Unidos, é hoje um dos mais respeitados estudiosos e pesquisadores da Comunicação Organizacional no mundo.

Sua relevância na área pode ser identificada pelo número de premiações recebidas ao longo de sua carreira, dadas por instituições associativas acadêmicas de renome. Citem-se alguns: Award for Outstanding Scholarly Book (produção do melhor livro acadêmico da área), da National Communication Association (NCA), por meio da sua Divisão de Pesquisa em Comunicação Organizacional, em 2004 e 2005; Fredric M. Jablin Memorial Award for Outstanding Member (prêmio Fredric M. Jablin para membro de destaque), da International Communication Association (ICA), em 2005; Award for Outstanding Scholarly Book (produção do melhor livro acadêmico da área), da International Speech Communication Association (Isca), por meio da sua Divisão de Pesquisa em Comunicação Organizacional, em 1988 e 1989; Award for Outstandig Scholarly Article (produção do melhor artigo acadêmico-científico da área), da Isca, em 1985, 1986, 1987 e 1996.

Em 2007 teve cinco artigos reproduzidos no já renomado livro Major works in organizational communication (Sage), editado por Linda Putnam e Kathy Krone, uma obra de cinco volumes que reúne a reprodução de artigos considerados pelos pares como "os clássicos da Comunicação organizacional" dos últimos trinta anos.
Com mais de cinquenta artigos publicados em periódicos acadêmicos de abrangência internacional, Mumby foi convidado para a conferência inaugural do III Congresso Brasileiro Científico de Comunicação Organizacional e Relações Públicas - Abrapcorp 2009, realizado de 28 a 30 de abril, em São Paulo (SP). Ele abordou o tema central, "Comunicação, humanização e organizações". Com o título "Reflexões do Professor Dennis Mumby", Alessandra Brandão fez uma síntese dessa palestra, disponível em http://www.blogger.com/ feeds / 2409256537811291604 / posts / default?start-index $=26$ e que reproduzimos aqui.

"Hoje em dia as organizações não mais se preocupam apenas com a fabricação de produtos, mas principalmente em agregar valores e significados (políticos, sociais e democráticos) a eles. Não é simplesmente o produto, e sim a criação da marca, capaz de 'amarrar' o produto a qualquer emoção humana e ser exatamente como a sociedade quer que ela seja. Os consumidores desejam estabelecer um relacionamento com a marca, ao passo que as organizações querem conectar-se com seus públicos e completá-los emocionalmente, por meio do chamado 'emotional branding'”.

"Comunicação não é alguém dando informações a outra pessoa. Comunicação envolve humanizar” (Mumby).

"Dessa forma, o papel da empresa vai muito além de simplesmente fornecer produtos com a função que lhe foi primeiramente atribuída. É preciso que a empresa disponha de um canal para 
ouvir os públicos, tanto fora quanto dentro dela. O Professor Dennis salienta que nós deveríamos ser melhores em ouvir. Deveríamos entender que 'cada conversa é uma oportunidade para aprender algo que não sabíamos antes daquela conversa' e é, portanto, uma possibilidade de mudança”.

"Ahumanizaçãono contextoorganizacionaléum tópico de muita relevância. As pessoas não devem ter receios de serem como são e, o mais importante, devem ser aceitas deste jeito. Essa "violência simbólica", que é o sistema da diferença, no qual algumas pessoas valem menos do que as outras, deve ser trabalhada para ser extinta".

"Humanizando organizações, a profitabilidade aumentará e teremos um emotional labor, ou seja, um ambiente de trabalho em que 'as pessoas não apenas aceitarão as diferenças dos outros e pronto, elas as acoplarão"”.

Após o evento, Mumby também ministrou, nos dias 02, 04 e 05 de maio, o curso "Estudos de Comunicação Organizacional em uma perspectiva crítica", desenvolvido em três temas: "Teoria e metateoria da tradição crítica"; "O fazer da pesquisa crítica: poder e controle no local de trabalho; e "Estudos organizacionais de gênero". No curso o professor mostrou como nos últimos 25 anos testemunhamos uma mudança de paradigma no modo como estudamos as organizações. Baseados em várias teorias da filosofia contemporânea, os pesquisadores de Comunicação Organizacional têm explorado as organizações como locais discursivos de formação de sentido e identidade. Essa abor- dagem é um contraste claro com as pesquisa dos anos 1960 e 1970, quando se tratavam as organizações como pouco mais do que recipientes para o estudo da transmissão de informações. Atualmente, questões sobre poder, discurso, identidade, diversidade e democracia tornaram-se centrais na tentativa de entender o processo organizacional. O propósito do curso foi caracterizar essa pesquisa mais contemporânea e avaliar seu impacto em nossa percepção da vida organizacional. Em particular, Mumby explorou o neo-marxismo, o pós-modernismo e o feminismo, examinando suas similaridades e diferenças.

Como estudioso da Comunicação Organizacional, Mumby é seguidor da teoria crítica e um dos introdutores de novas frentes de estudo na Comunicação Organizacional, relacionadas aos estudos de gênero e do humor no contexto das organizações. Ele mesmo apresenta a atividade em que se envolve no momento. "Minha pesquisa atual tem como foco as relações entre discurso, poder e organização. Estou particularmente interessado em processos de controle e resistência, bem como nas formas como essa dialética é discursivamente produzida, mantida e reproduzida. Correlatamente, interessa-me explorar a relação entre gênero e identidade, bem como examinar de que forma os processos de controle e resistência organizacional se ligam com as identidades organizacionais de gênero. Também estou trabalhando em um livro-texto (manual) sobre Comunicação Organizacional. Será o primeiro desse tipo a ser escrito nessa área usando a teoria crítica como perspectiva organizacional". 
Nesta entrevista para Organicom, Mumby conversa conosco sobre a sua visão de Comunicação Organizacional, seus interesses de pesquisa, tendências da área e sua percepção do que seja a Comunicação Organizacional brasileira, em comparação com a norte-americana.

Organicom - Professor Dennis, antes de mais nada, nosso agradecimento por ter aceitado conceder-nos esta entrevista para a revista Organicom.

Dennis Mumby - Eu é que agradeço pela oportunidade desta entrevista. Minha viagem a São Paulo, em abril deste ano, para participar do III Congresso da Abrapcorp, foi uma experiência maravilhosa e enriquecedora. Foi minha primeira experiência de Brasil. Aprendi muito conversando com estudiosos brasileiros. Recebo com alegria esta chance de falar sobre questões relacionadas à Comunicação Organizacional.

Organicom - Que tal começarmos esta entrevista com você nos contando o que entende por Comunicação Organizacional?

Dennis Mumby - É difícil responder esta questão de maneira direta, já que a Comunicação Organizacional se expandiu de diversas formas. Em termos bem simples, em seu contexto norte-americano, a Comunicação Organizacional pode ser descrita como um subcampo dentro do campo da Comunicação, tendo surgido inicialmente no meio da década de 1950, com foco em "Comunicação Industrial e de Negócios". Ao longo dos últimos cinquenta anos, ela se ex- pandiu para incluir muitos domínios de estudo, metodologias e abordagens teóricas diferentes.

Entretanto, o termo "comunicação organizacional" é exclusivo do campo da Comunicação, caracterizando estudos produzidos no âmbito ou sob a sua ótica. Estudiosos da Comunicação Organizacional trabalham em departamentos com colegas de outras áreas de pesquisa da Comunicação, como Retórica, Comunicação Interpessoal, Comunicação de Massa, Comunicação de Saúde e assim por diante. Eu sei que no Brasil a Comunicação Organizacional e as Relações Públicas são bastante unidas, mas o mesmo não acontece nos Estados Unidos. Meu departamento, por exemplo, não contempla um programa de Relações Públicas, embora nossa Escola de Jornalismo o possua. Então, parte do problema em responder esta pergunta diretamente é que o campo maior da Comunicação é notavelmente interdisciplinar e tem desenvolvido configurações diferentes de subcampos em diferentes instituições.

Apesar dessa falta de uma concepção clara de Comunicação Organizacional, nosso campo é caracterizado por fortes ligações entre membros

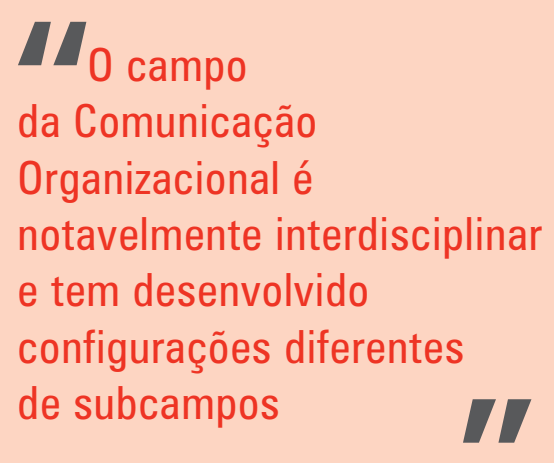


de uma comunidade de estudiosos que estão verdadeiramente interessados em promover um campo que dá valor a uma multiplicidade de teorias e métodos... Sim, temos debates vigorosos sobre o valor de diferentes abordagens para estudar a Comunicação Organizacional, mas damos valor à força na diversidade. Acho que este é um dos motivos por que somos capazes de desenvolver fortes ligações com outros campos de conhecimento e outras disciplinas, como os Estudos das Organizações, a Administração e a Psicologia.

Ou seja, não estamos interessados em "policiar" os limites de nosso campo e decidir quem pode ou não pode ser um membro de nossa comunidade, quais indivíduos podem se unir ou não a ela. Acredito que esse não é o caso de muitos campos, em que os limites acadêmicos são frequentemente impostos e demarcados de forma cuidadosa.

Organicom - Quais as exigências, nos Estados Unidos, em termos de formação profissional, para alguém que deseje se tornar um "comunicador organizacional"?

Dennis Mumby - Não há exames formais ou um processo de acreditação para estudantes de Comunicação Organizacional. Geralmente, eles fazem cursos de Comunicação Organizacional como parte da sua formação em Comunicação, que, por sua vez, é parte de uma formação mais ampla em Ciências Humanas e Sociais. Nesse sentido, os estudantes não são treinados para assumir posições de trabalho específicas de comunicação em organizações, mas lhes são ensinadas habilidades analíticas amplas que são

\section{$\Delta$ Vivemos em uma \\ cultura dramatúrgica \\ baseada em performance, que explora como os atores sociais enact significados \\ e identidades na sua \\ vida cotidiana}

adaptáveis a um extenso conjunto de posições profissionais.

Se estiver em um programa cujo curso tem foco em Comunicação Organizacional, um estudante cursa tipicamente disciplinas como: liderança; dinâmica de grupo; cultura organizacional; teoria organizacional; ética e comunicação organizacional; responsabilidade social corporativa; métodos de pesquisa; e disciplinas congêneres. Em nível de doutorado, geralmente os alunos estão se preparando para uma carreira acadêmica, embora um número reduzido obtenha a titulação e logo busque emprego no mercado.

Organicom - Apesar de a Comunicação Organizacional, nos Estados Unidos e em vários outros países, não ter características de prática profissional, como você já disse, que papel você atribuiria ao planejamento estratégico nesse campo de conhecimento?

Dennis Mumby - A realidade é que questões de planejamento estratégico - pelo menos no sentido em que tradicionalmente esse termo é utilizado nos estudos de Administração - não são um ponto importante na pauta 
da ampla maioria dos pesquisadores de Comunicação Organizacional. Na pesquisa crítica, a ideia de intervenção e transformação social exerce um papel importante, com o pesquisador sendo posicionado como um agente da mudança social; em tais contextos, o planejamento estratégico se torna muito mais importante. Por exemplo, minha colega Pat Parker, da Universidade do Colorado, está engajada em um projeto de longo prazo com dois bairros de baixa renda na cidade de Chapel Hill, na qual a universidade está localizada. Como parte de seu esforço de intervenção (em que colaborou com residentes locais), ela fundou o Ella Baker Center for Leadership. Esse centro trabalha com mulheres adolescentes afro-americanas para desenvolver projetos de intervenção baseados na comunidade e proporcionar a elas experiências de liderança que se traduzirão em oportunidades de uma vida melhor. Esse tipo de projeto de comprometimento baseado na comunidade naturalmente requer bastante planejamento estratégico, incluindo trabalhar com membros da comunidade para estabelecer planos de ação e objetivos, envolver-se com solicitações de financiamento, procurar doa-

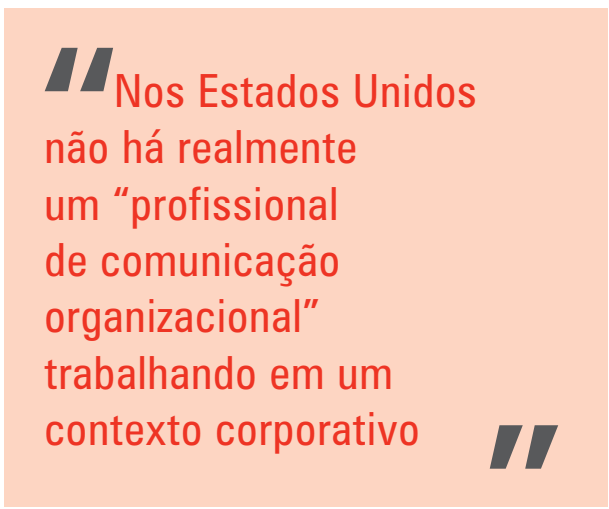

dores etc. Então, nesse tipo de projeto baseado na comunidade, o planejamento estratégico tem uma importância central. Eu argumentaria que, se os estudiosos de orientação crítica assumirem mais seriamente projetos de comprometimento com diferentes grupos de stakeholders que levem à real mudança social, o planejamento estratégico precisa ser mais seriamente um foco, tanto da perspectiva teórica quanto da prática.

Organicom - O que faz um profissional de comunicação organizacional nos Estados Unidos?

Dennis Mumby - Bem, de um modo geral, a Comunicação Organizacional, nos Estados Unidos, é um empreendimento acadêmico e por isso não temos uma noção do "profissional de comunicação organizacional" tão desenvolvida como no Brasil. Então, no geral, não há realmente um "profissional de comunicação organizacional" trabalhando em um contexto corporativo. Isto não significa que não tenhamos pessoas em nosso campo que dão consultorias ou trabalham com organizações sobre questões relacionadas à Comunicação. Há vários professores que assessoram organizações, transpondo a divisão entre os mundos acadêmico e corporativo.

Organicom - Quando um pesquisador de Comunicação Organizacional tem a possibilidade de analisar uma organização, qual deve ser o seu principal interesse?

Dennis Mumby - Novamente, não há uma resposta simples para esta questão, principalmente em 2009. Particularmente desde o começo da década 
de 1980, o campo se expandiu de tal forma que se tornou tremendamente eclético quanto a abordagens e interesses dos estudiosos de Comunicação Organizacional. Em termos bem amplos, talvez a maior inovação nos últimos 25 anos tenha sido o fato de que os pesquisadores tomaram como um ponto focal a vida cotidiana de membros da organização. O que isto significa em termos de pesquisa é que os estudiosos realmente se interessaram em examinar e explorar processos comunicativos. Uma das ironias de nosso campo é que por muito tempo os pesquisadores não prestaram muita atenção à "comunicação" na Comunicação Organizacional; mesmo quando eles alegavam estudar processos de comunicação, o que estavam realmente fazendo era analisar os resultados de surveys ou dados de experimentos. Ao se voltarem ao estudo de processos reais de comunicação (conversa cotidiana, narração de histórias, rituais, metáforas etc.), os pesquisadores começaram a examinar a verdadeira "matéria" da organização, isto é, o que torna uma organização uma organização.

Então, para responder a questão, eu diria que um pesquisador deve estar fundamentalmente interessado em como os membros da organização constroem comunicativamente o organizing ${ }^{1}$ no nível da vida organiza-

1 Organizing, termo originariamente utilizado por Mumby em inglês, em português teria como tradução literal "organizando". 0 uso de termos no gerúndio é resultado de um modismo vigente na literatura especializada de várias áreas, inclusive na Comunicação Organizacional, para, com isso, indicar a existência de uma dinâmica viva, de um contínuo movimento naquilo em que o gerúndio é utilizado - no caso, no organizar. A ênfase aqui é

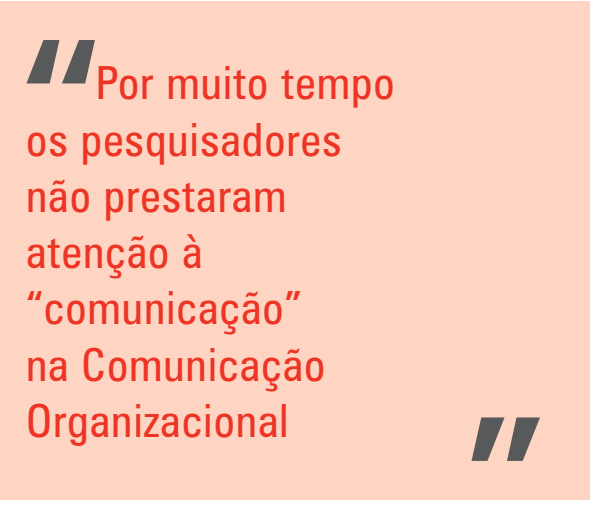

cional cotidiana. Em outras palavras, compreender as organizações é uma questão de entender como membros se envolvem coletivamente em processos de produção de sentido por meio de práticas de comunicação e de que maneira, como resultado, as realidades organizacionais são construídas. De forma alguma isso significa que os pesquisadores devam procurar uma realidade organizacional única. Pelo contrário, acho que algumas das pesquisas mais interessantes ao longo das últimas décadas forneceram visões das complexidades, multiplicidades e contradições do processo de organizing, mostrando-o de várias formas como precário, contestável e cheio de incertezas.

Organicom - No curso "Comunicação Organizacional de uma perspectiva crítica", que ministrou no Brasil como parte das atividades do III Abrapcorp, vocêfez referência à performance ethnography (etnografia performática) como uma

no caráter dinâmico, intermitente e formativo do processo de organizar. Algumas vezes inclusive nesta entrevista - organizing tem sido utilizado como sinônimo de uma concepção mais contemporânea de organização. (Nota da revisora técnica). 
nova e interessante técnica de pesquisa em uso por alguns pesquisadores de Comunicação Organizacional. Do seu ponto de vista, quais são os prós e os contras dessa técnica? O que ela agrega às técnicas mais comumente utilizadas?

Dennis Mumby - Devo esclarecer que não sou usuário da performance ethnography. Entretanto, vários de meus colegas, em um subcampo da Comunicação chamado Estudos de Performance, se interessaram muito pela ideia do "performativo", que surge originalmente na obra de Judith Butler e outros. Muito dessa obra se interessa em como identidades sociais são construídas e "desempenhadas" momento a momento; isto é, a identidade é examinada como performativa e não como fixa e estável. Na Comunicação Organizacional, a ideia de uma abordagem performativa é atraente porque enfatiza a noção de organizing como enacted ${ }^{2}$ e performada por meio de práticas comunicativas cotidianas. Nesse sentido, nós "fazemos" gênero, "fazemos" raça, "fazemos" sexualidade e assim por diante. Dessa maneira, a performance ethnography enfatiza que vivemos em

2 Enact é um termo que, na literatura especializada de várias áreas, inclusive na Comunicação Organizacional, tem sido mantido no original por não ser possível fazer dele uma tradução literal para o português no sentido em que tem sido utilizado nessas literaturas, que é o sentido a ele atribuído por Weick na sua obra The social psychology of organizing (1973). A tradução para enact encontrável nos dicionários inglês-português usuais, como por exemplo, no Houaiss On Line e no Webster's é de sancionar, promulgar, ordenar, dar força de lei. Enact no sentido dado por Weick se refere à expressão da capacidade de agentes darem vida à ação. (Nota da revisora técnica).

\section{$\Delta$ A ideia de \\ uma abordagem \\ performativa \\ é atraente \\ porque enfatiza \\ a noção de organizing \\ como enact}

uma cultura dramatúrgica baseada em performance (emprestando o termo de Erving Goffman), sendo seu objetivo explorar como os atores sociais enact significados e identidades (além de sistemas de diferença) na sua vida cotidiana. Para o etnógrafo performático, as performances cotidianas são textos a serem interpretados, e textos podem ser performados. Então, às vezes os dados etnográficos são vertidos em performances ao vivo ou filmadas e não em textos acadêmicos. O recente documentário de Dwight Conquergood, The heart broken in half, é um exemplo clássico de performance ethnography - um estudo etnográfico de dois anos sobre a cultura das gangues de Chicago que, como filme, tem um impacto muito diferente na audiência do que um artigo acadêmico sobre o assunto. Não há muitos pesquisadores de Comunicação Organizacional produzindo performances ao vivo ou filmes em vez de artigos acadêmicos, mas certamente é uma forma intrigante de prestar contas de como se dá a vida organizacional. Quem sabe - talvez no futuro tais performances se tornem eventos comuns em congressos de estudos organizacionais! 
Organicom - Durante a sua estada no Brasil, você comentou que a abordagem crítica define o que hoje é o campo da Comunicação Organizacional. Poderia explicar melhor esse seu ponto de vista?

Dennis Mumby - Bem, acho que eu teria problemas com muitos de meus colegas se eles vissem, em um texto escrito e publicado, que eu disse que a perspectiva crítica define o campo da Comunicação Organizacional! Nos últimos vinte anos, aproximadamente, ela certamente se tornou uma abordagem muito importante no campo e tem, de muitas maneiras, redefinido o que conta como objetos legítimos de estudo na Comunicação Organizacional. O que a perspectiva crítica tem feito para o campo, no meu modo de ver, foi, fundamentalmente, enfraquecer a ideia de que as organizações são simplesmente locais de tomada de decisão racional onde poder e política são fenômenos idiossincráticos e anômalos. Antes de a perspectiva crítica vir à cena, o termo "poder" era, de forma generalizada, visto como um palavrão e amplamente ignorado como um fenômeno legítimo de estudo. Hoje, diante da aceitação de que as organizações e

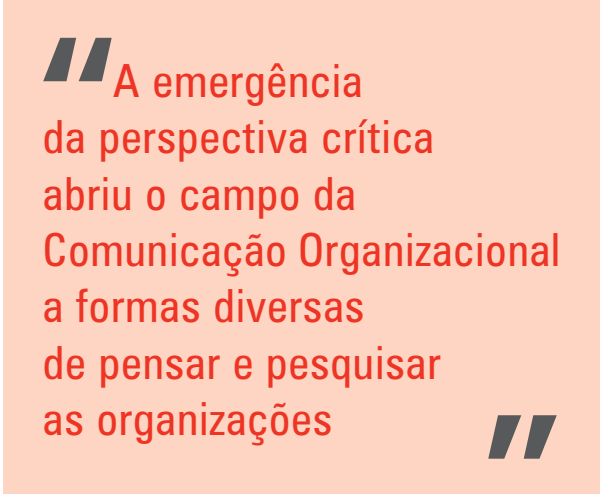

os processos organizacionais são, por definição, políticos por natureza, a ideia é bastante aceita. E de muitas formas minha carreira acadêmica pode ser descrita como um esforço para explorar sistematicamente as relações entre comunicação, poder e organização (o título de meu primeiro livro, em 1988, foi Communication and power in organizations - Comunicação e poder nas organizações -, tendo sido a primeira investigação sobre organizações e poder feita no campo da Comunicação Organizacional, e com o porte de publicação em livro, que adotou explicitamente uma perspectiva crítica).

A emergência da perspectiva crítica, na minha opinião, realmente abriu o campo da Comunicação Organizacional a formas diversas de se pensar sobre as organizações e de pesquisálas. Uma vez que você enfraquece a sua concepção de assuntos como gerenciamento, estratégia, cultura etc. enquanto processos puramente racionais e, ao contrário, os visualiza como caracterizados por jogos de poder, resistência, esforços para moldar a realidade organizacional, e assim por diante, passa a ter uma visão muito mais interessante e "texturizada" das formas como as pessoas constroem suas vidas organizacionais.

Então, acho que, de muitas maneiras, a perspectiva crítica é um esforço para "tirar dos trilhos" a ideia de business as usual (os negócios como de praxe) e enfraquecer a ideia de que a perspectiva gerencialista é o padrão, o modo de estudar as organizações pelo "senso comum”. Tomo emprestada de Michael Burawoy, um sociólogo organizacional, a principal questão da perspectiva crítica, que não é "por que as pessoas 


\section{$\boldsymbol{U}_{\text {A perspectiva }}$ \\ crítica tira dos trilhos \\ a ideia de business \\ as usual e enfraquece \\ a ideia de que a \\ perspectiva gerencialista \\ é o padrão}

não trabalham mais?" e sim "por que as pessoas trabalham tanto?". Em outras palavras, o que é que muitas vezes instiga as pessoas a darem suas vidas e almas para organizações, geralmente negligenciando famílias, vidas pessoas etc.? Para responder à pergunta alternativa (ou seja, à não-gerencialista), uma pessoa deve começar de uma posição diferente e pensar em organizações e corporações como forças colonizadoras cujo objetivo é moldar a realidade para as pessoas. Quando fiz minha palestra no III Abrapcorp, uma das coisas que disse é que a corporação moderna odeia a ideia de que os seres humanos têm experiências com o mundo e entre si e "produzem sentido" de qualquer forma que não seja intermediada ou patrocinada por processos de corporativização. A abordagem crítica, conforme sugiro, analisa e critica os mecanismos discursivos pelos quais as corporações constroem realidades (frequentemente, de maneira arbitrária) que atendem seus interesses ao mesmo tempo em que, muitas vezes, prejudicam os interesses de outros stakeholders (por exemplo, comunidades locais, proprietários de pequenos negócios, fazendeiros sustentáveis etc.)
Além de criticar, a abordagem crítica tenta abrir possibilidades para pensar e praticar formas diferentes de organização. Como é uma democracia organizacional genuína? Qual é o papel da comunicação na criação de um organizing mais democrático? Qual é o papel dos pesquisadores de Comunicação Organizacional na geração de possibilidades democráticas? Estas são questões difíceis, mas acho que, para o trabalho crítico passar de um empreendimento meramente acadêmico, precisamos nos esforçar para achar as respostas.

Organicom - Ainda no curso que ministrou após o III Abrapcorp, no Brasil, você expressou o ponto de vista de que humor e gênero, hoje em dia, devem ser reconhecidos como temas de interesse da Comunicação Organizacional. Por que atribui essa importância a eles?

Dennis Mumby - O estudo do gênero já está presente por algum tempo na Comunicação Organizacional - pelo menos desde o começo da década de 1990. Estudos feministas tiveram forte influência no campo nos últimos vinte anos. Em seu início, os estudos críticos não prestavam muita atenção ao gênero, tendendo a tratar o poder de forma bastante genérica com foco reduzido em formas particulares de diferença. A questão da igualdade de gêneros tem sido um tema contínuo na sociedade norte-americana já há algumas décadas, mas apenas no início da década de 1990 os pesquisadores começaram a observar questões relacionadas com a criação de oportunidades iguais para mulheres para examinar a ideia, pioneiramente desenvolvida por Joan Acker, de que as organizações 
têm gênero. Isto é, em vez de pensar no gênero como um bem do indivíduo, devemos pensar nele como fundamentalmente estruturado na real construção das organizações e parte dos processos cotidianos de organização. Eu acho que esta é uma mudança importante, porque nos leva a ir além de pensar sobre comportamentos individuais ou políticas organizacionais, procurando mais examinar as formas pelas quais realidades organizacionais, identidades e sistemas de significado são pressupostos em unidades binárias de gênero (masculino/feminino, cultura/natureza,razão/emoção, dependente/independente e assim por diante).

Para mim, o interessante é que, nos últimos anos, a abordagem crítica deixou de pensar principalmente sobre gênero passando a ter como foco mais amplamente a questão da diferença e as formas com que a diferença é o meio e o resultado do organizing. Assim, questões de raça, sexualidade, classe, forma física etc. se tornaram parte da pauta crítica. Eu sugeriria que isto envolve um foco maior na questão da identidade humana e um interesse na organização como um dos principais lugares da

\section{$\boldsymbol{\Delta} \boldsymbol{\Delta}_{\mathrm{A} \text { abordagem }}$ \\ crítica deixou \\ de priorizar 0 gênero, passando a ter como foco mais amplo \\ a questão da diferença}

formação de identidade na sociedade contemporânea. Por exemplo, atualmente estou editando um projeto de livro chamado Organizing difference, contendo trabalhos que tratam da interseção de diferença e organização por meio de um conjunto amplo de assuntos. Alguns estudiosos de Comunicação Organizacional - Karen Ashcraft, por exemplo - argumentam que é um erro até mesmo falar sobre gênero separadamente de outras formas de diferença e que devemos tomar como foco as interseções de várias formas de diferença no processo de organização. Assim, analisar como, por exemplo, gênero, raça e sexualidade são articulados juntos deve ser nosso foco contínuo na pesquisa da diferença e da Comunicação Organizacional.

Acho que minha proposta de que o humor seja uma questão importante para a Comunicação Organizacional talvez expresse mais um desejo de minha parte do que qualquer outra coisa. É um interesse pessoal meu (e sem dúvida o motivo de eu ter falado sobre isso), mas ainda é uma área relativamente pouco explorada. Sim, tem havido alguma pesquisa nessa área, incluindo um livro recente editado por Carl Rhodes e Robert Westwood, para o qual contribuí com um capítulo. Em minha opinião, o humor tem sido estudado recentemente porque é uma característica que permeia todos os meandros organizacionais. $\mathrm{O}$ local de trabalho seria um lugar terrivelmente chato se ninguém contasse piadas ou ocasionalmente se soltasse e agisse como bobo. Com o domínio das perspectivas gerencialista $\mathrm{e}$ funcionalista, havia pouco incentivo para estudar o humor, porque ele era 
visto não apenas como trivial, mas também como um impedimento à eficiência e produtividade. De fato, a administração tradicionalmente tentou controlar o humor e a brincadeira e procurou limitar seus efeitos nos resultados da empresa.

É claro, o humor é parte da condição humana e, por extensão, tem uma presença importante nas práticas cotidianas de organização. Então, em parte, acho que ele se tornou um objeto de estudo crítico precisamente por causa de sua cotidianidade. Além disso, o humor também tem sido teorizado como meio de resistência no local de trabalho e, claramente, a abordagem crítica passou bastante tempo estudando as formas de resistência individual e coletiva dos trabalhadores a processos de controle administrativogerencial. Assim, diversos pesquisadores (por exemplo, David Collinson, Peter Fleming, Steve Linstead, para citar alguns) têm se interessado pelas formas de atuação do humor na construção de discursos organizacionais e na produção de sentido de modo a permitir que os trabalhadores subvertam a lógica administrativo-gerencial dominante e os sistemas de racionalidade. Entendo que a pesquisa sobre

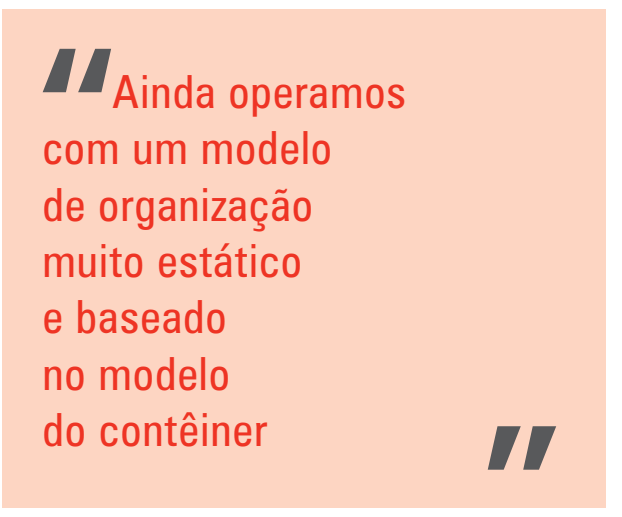

humor também é consistente com a virada pós-moderna em direção ao estudo da ironia e do cinismo no local do trabalho - dois elementos que são muitas vezes integrados ao uso do humor.

Organicom - Dennis, que questões e problemas comunicacionais são enfrentados pela Comunicação Organizacional?

Dennis Mumby - Eu poderia responder a essa questão de várias maneiras. Acho que um problema é que, como campo, nós ainda tendemos a ter um foco excessivo nos contextos organizacionais corporativos. Essa situação tem melhorado, mas ainda gostaria de nos vermos indo mais além dos tipos de organização que estudamos para incluir organizações sem fins lucrativos, grupos de voluntariado, movimentos sociais etc. Além disso, acho que ainda operamos com um modelo de organização muito estático e baseado no modelo do contêiner. Vemos as organizações como lugares "nos quais" as pessoas trabalham e as pesquisamos como tais, em vez de pensarmos sobre as práticas de organização e as formas com que as pessoas se organizam por meio da comunicação e de sistemas de significação fora do contexto físico das organizações. Por exemplo, a pesquisa sobre identidades profissionais (o trabalho de Karen Ashcraft sobre pilotos de avião me vem à mente) não é realmente o estudo de uma organização específica e sim uma investigação de como um grupo de pessoas se organiza ao redor de um conjunto de discursos, identidades e corpos de conhecimento historicamente produzidos. Entendo que tal trabalho é 


\section{$\Delta \boldsymbol{\Delta}_{\text {Questões de raça, }}$ sexualidade, classe, forma física etc. se tornaram parte da pauta crítica. Isto envolve um foco maior na questão da identidade humana}

empolgante porque realmente coloca o discurso - em níveis tanto macro quanto micro - no centro dos processos de organizar e mostra como realidades organizacionais surgem de embates complexos por controle sobre quem consegue moldar os sistemas de significação organizacionais.

Além disso, parece-me que aceitamos rapidamente demais e indiscriminadamente a ideia de comunicação como constitutiva das organizações. Acho que essa ideia é profunda, mas muitas vezes a aceitamos como dada em vez de tomá-la como uma problemática que requer explicação e investigação detalhadas. Além disso, aceitar esse princípio tende a deixar passar desapercebido o fato de que as organizações são estruturas materiais que produzem consequências reais para pessoas reais. Nesse sentido, a comunicação também é material, além de simbólica, no que cria realidades que possuem consequências materiais no mundo. Assim, sem entrar em muitas complexidades, a relação entre o comunicativo e o material é um assunto ao qual os estudiosos de Comunicação Organizacional precisam continuar voltando seus esforços de pesquisa.
Organicom - Você acredita que a Comunicação Organizacional possa ser vista como uma manifestação empirica do objeto comunicacional?

Dennis Mumby - Esta certamente é a crença de muitos estudiosos de Comunicação Organizacional. A "Escola de Montreal”, particularmente, passou os últimos quinze anos desenvolvendo o que eles chamam de modelo CCO (Communicative Constitution of Organization-Constituição Comunicativa das Organizações), de organizing no qual o foco está na análise do texto e da conversação para ilustrar as formas com que esses mecanismos comunicativos constituem o que chamamos de organização. Entretanto, em vez de descrever as organizações como a "manifestação empírica" da comunicação, eu diria que as organizações são tanto o meio quanto o resultado dos processos de comunicação. Isto é, a comunicação é componente da organização, mas ao mesmo tempo a organização age de volta na comunicação para funcionar como contexto semântico e estrutural para processos de comunicação. É famosa a afirmação do antropólogo Clifford Geertz de que "o homem é um animal amarrado a teias de significados que ele mesmo teceu". Acho que não é insensato imaginar as organizações como "teias de significação" dentro das quais os homens, como seres comunicativos, estão amarrados. Nós, comunicativamente, produzimos organizações e somos produzidos pelas organizações.

Organicom - Você acredita que as bases teóricas da Comunicação Organizacional provêm uma teoria comunicacional das organizações? 
Dennis Mumby - A questão da relação entre comunicação e organização tem estado no centro dos estudos de Comunicação Organizacional por muitos anos. Os estudiosos há muito tempo vêm se esforçando em encontrar uma resposta para como melhor conceptualizar uma teoria da comunicação das organizações. Como mencionei anteriormente, um fato estranho em relação às décadas iniciais de nosso campo é que a maioria dos pesquisadores de forma nenhuma estava realmente estudando Comunicação. Acho que é em parte por esse motivo que os pesquisadores hoje põem o foco particularmente na relação comunicação-organização. Além disso, parece-me que a questão das teorias comunicacionais sobre as organizações é vista como uma forma com que nosso campo pode fazer contribuições importantes para o estudo interdisciplinar das organizações; isto é, outros campos estudam as organizações (Administração, Sociologia, Psicologia etc.), mas nós gostamos de pensar que nenhum deles é capaz de trazer sofisticação teórica para o estudo de organizações enquanto construções comunicativas como nós fazemos.

Acho, sim, que o trabalho teórico que temos feito em nosso campo proporciona algumas teorias comunicativas sólidas das organizações. A ideia de que as organizações são construções comunicativas é ao mesmo tempo simples e profunda. Por um lado, é uma ideia simples dizer que as organizações são estruturas comunicativas que funcionam principalmente por meio das interações cotidianas dos seus membros. Por outro lado, examinar verdadeiramente as com-

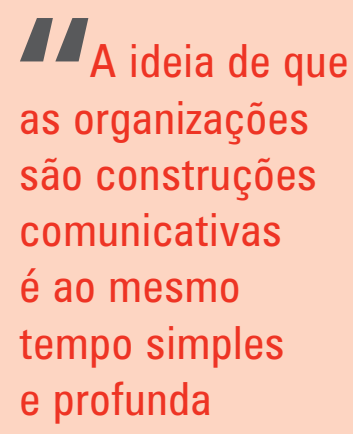

plexidades e texturas da constituição comunicativa das organizações exige teorias robustas e métodos sofisticados. As organizações são estruturas comunicativas e sociais notavelmente complexas, e há uma estabilidade para essa estrutura e também uma percepção de que elas são precárias e constituídas e reconstituídas na dinâmica de momento a momento. A Comunicação é o que faz a organização possível, mas isto também significa que as organizações não são as estruturas estáveis e invariáveis que o senso comum nos diz que são. Como Karl Weick disse certa vez, “a palavra 'organização’ é um substantivo, mas é também um mito." Weick estava enfatizando a necessidade de falar sobre a organização como um processo, como organizing, e não, como uma entidade fixa; mas ele poderia também estar falando sobre o fato de que as organizações realmente existem apenas nas práticas de comunicação diárias rotineiras de seus membros.

Organicom - Tomando por referência o que leu, viu, ouviu e vivenciou em termos do que seja a Comunicação Organizacional no Brasil, você diria que aqui existe um 
pensamento e prática de Comunicação Organizacional que são diferentes da concepção mainstream (do que seja Comunicação Organizacional)?

Dennis Mumby - Como disse no início de minhas observações, foi uma experiência tremendamente gratificante visitar o Brasil e falar para estudiosos e estudantes de Comunicação Organizacional. Há claramente um trabalho muito estimulante acontecendo aí. Baseado em minha limitada experiência, eu diria que há um par de coisas vem a minha mente em termos de caracterizar a comunicação Organizacional no contexto brasileiro.

Em primeiro lugar, está claro que o campo está bem vinculado às Relações Públicas; de fato, as duas áreas parecem ser concebidas como uma só, aí no Brasil. Fiquei muito surpreso ao ser perguntado sobre o estudo de Relações Públicas quando estava em São Paulo - um campo de estudos sobre o qual eu não sei praticamente nada à respeito! Mas também me parece que aí as próprias Relações Públicas são concebidas de forma bem diferente da configuração norte-americana. Sendo justo

\footnotetext{
$\boldsymbol{\Psi}_{\text {Não é insensato }}$

imaginar as organizações

como 'teias de

significação' dentro das

quais os homens, como

seres comunicativos, estão amarrados
}

ou não, eu diria que o estudo das Relações Públicas nos Estados Unidos é visto como um empreendimento bastante conservador e vinculado aos interesses corporativos. Por outro lado, me parece que no Brasil as Relações Públicas são concebidas de maneira mais progressista politicamente e não estão tão "amarradas" à vida corporativa. De fato, me parece que o estudo e a prática de Relações Públicas aí são bastante situados no contexto de questões de justiça social e democracia.

Relacionado a isso, a minha percepção é de que o estudo da Comunicação Organizacional no Brasil possui uma forte orientação à práxis, com preocupações com o desenvolvimento de práticas de comunicação fortes e democráticas nas organizações. Se puder fazer uma comparação entre os estudos norte-americanos e brasileiros de Comunicação Organizacional, eu diria que os Estados Unidos primeiro desenvolveram, nos últimos vinte anos ou mais, uma forte base teórica e só em anos relativamente recentes passaram ao estudo empírico e crítico de questões como democracia, ética, responsabilidade social corporativa etc. No Brasil, por outro lado, os estudos de Comunicação Organizacional desde o início parecem ter sido fortemente fundamentados em questões de democracia, justiça social etc. e só recentemente começaram a voltar-se ao desenvolvimento de arcabouços teóricos que acompanham esse tipo de orientação centrada na práxis. Nesse sentido, os estudos brasileiros possuem uma ligação íntima com questões sociais mais amplas que, no meu modo de ver, os estudiosos 


\section{$\boldsymbol{U}_{\text {Os pesquisadores }}$ \\ de Comunicação \\ Organizacional \\ nos Estados Unidos \\ estão se \\ tornando menos \\ insulares}

norte-americanos estão apenas começando a compreender.

O campo da Comunicação Organizacional, no Brasil, é estimulante e vibrante. Espero ansiosamente pelo desenvolvimento de relações mais próximas entre os estudiosos brasileiros e os norte-americanos. Acho que podemos aprender muito uns com os outros. Por isso, repito que fico muito feliz em poder estar conversando com os leitores de Organicom sobre isso.

Organicom - Uma última questão, Dennis: qual é a sua avaliação sobre "o estado da arte" e seu ponto de vista sobre tendências da Comunicação Organizacional?

Dennis Mumby - Acho que o campo provavelmente está mais estimulante e vibrante do que nunca. Algo que aconteceu nos últimos cinco, dez anos é o desenvolvimento de fortes ligações entre estudiosos de Comunicação Organizacional norte-americanos, europeus e australasiáticos em estudos organizacionais críticos. Por exemplo, o The Sage handbook of organizational discourse, editado por David Grant, Cynthia Hardy, Clifford Oswick e Linda Putnam em 2004, é uma importante coletânea que compila trabalhos de estudiosos da Comunicação Organizacional baseados nos Estados Unidos e de estudiosos críticos de Estudos Organizacionais australianos e europeus. Para mim, essa obra é importante para ilustrar as diversas ligações entre Comunicação Organizacional e Estudos Organizacionais (ou pelo menos entre as pessoas que produzem trabalho crítico nessas áreas), além de mostrar as contribuições de estudiosos de Comunicação Organizacional para entender as organizações como fenômenos discursivos.

De um modo mais geral, me parece que o campo continua a se engajar em pesquisa inovadora em várias áreas. Está claro que os estudiosos estão expandindo suas agendas de pesquisa para além das corporações e estudando vários outros contextos organizacionais, incluindo organizações sem fins lucrativos, ONGs, grupos feministas etc. Acho que essa mudança representa um desejo de explorar formas alternativas de organizing e de possibilitar o desfrute de formas organizacionais mais humanas e democráticas. Dados os impulsos utópicos e emancipadores da teoria crítica, essa mudança é muito consistente com essa filosofia.

Isso se dá também porque os pesquisadores de Comunicação Organizacional nos Estados Unidos estão se tornando menos insulares, tanto por causa de suas fortes ligações com estudiosos de outras áreas quanto por causa de seus esforços para estudar a Comunicação Organizacional de maneira mais global. Como membro de vários conselhos editoriais, estou vendo um número crescente de ma- 
nuscritos de estudiosos baseados nos Estados Unidos que pesquisam as organizações globalmente. Além disso, esses estudiosos estão se tornando mais sensíveis ao estudo de organizações globais, ao mesmo tempo em que prestam atenção a assuntos organizacionais específicos da cultura. Nosso periódico mais importante da área, o Management Communication Quarterly, se tornou crescentemente internacionalizado sob a edição de Jim Barker, não apenas publicando trabalhos de estudiosos de todo o mundo (inclusive do Brasil), mas também trabalhos que tratam cada vez mais de questões internacionais / globais.

Outras tendências atuais na pesquisa de Comunicação Organizacional incluem um foco no equilíbrio trabalho-vida. Muitos pesquisadores estão interessados nas maneiras como o surgimento da forma organizacional pós-fordista e a ruptura da tradicional separação entre trabalho e vida familiar criaram desafios importantes para os empregados, particularmente em torno de questões de identidade, comunicação e trabalho de conhecimento. O fim da organização fordista e o surgimento do pós-fordismo gerou muita pesquisa - grande parte dela crítica - sobre o "trabalhador do conhecimento" e as maneiras pelas quais o trabalho administrativo está crescentemente sujeito a várias práticas de controle discursivas e nãodiscursivas. Amplia-se também a pesquisa sobre diferença e organização como já falei antes, os estudiosos de Comunicação Organizacional estão desenvolvendo concepções mais amplas de diferença, que vão além de um foco principal no gênero para examinar as maneiras como várias formas de diferença se cruzam no processo de organizing. Por fim, alguns pesquisadores estão menos interessados no estudo das organizações per se e mais em como comunicação e discursos organizam identidades por exemplo, diversos pesquisadores estão estudando a construção discursiva de profissões (como o trabalho de Karen Ashcraft sobre pilotos de avião), em um esforço para entender como as profissões funcionam como sistemas de significação e poder que constroem identidades de formas inclusivas e exclusivas.

Então, o estado do campo é vibrante e de um pluralismo saudável, em que muitas teorias e métodos de pesquisa coexistem em um esforço para entender as complexidades da vida organizacional. Para mim, o que continua sendo excitante e inspirador é a maneira como os estudiosos estão desenvolvendo e explorando perspectivas verdadeiramente comunicacionais no estudo das organizações, maneiras em que processos comunicacionais e discursivos são levados a sério como características importantes e decisivas da vida organizacional. No início de minha carreira acadêmica, parecia ser uma batalha constante procurar mover estudiosos para além do campo da Comunicação Organizacional, levando-os a considerar a comunicação como um fenômeno a ser estudado. Este é cada vez menos o caso, já que, no mundo todo, estudiosos da Administração, Sociologia, Psicologia e Linguística estão se voltando cada vez mais para nosso trabalho como fonte. 